\title{
FORMAÇÃO DE TRINCAS POR FRAGILIZAÇÃO POR METAL LÍQUIDO EM LENTES DE SOLDA DE AÇO DUAL PHASE COM REVESTIMENTO *
}

\author{
Gabriela Pereira de Miranda ${ }^{1}$ \\ Sergio Luiz Vieira ${ }^{2}$
}

\begin{abstract}
Resumo
Os aços avançados de alta resistência do tipo dual phase (DP) são aplicados na indústria automobilística, principalmente, em componentes estruturais. Alguns desses aços são revestidos com zinco e suas ligas, visando maior resistência à corrosão. Atualmente, o processo de união de aços mais utilizado em veículos é a soldagem por pontos. O emprego inadequado de parâmetros de soldagem pode provocar trincas por fragilização por metal líquido (LME, do inglês liquid metal embrittlement) em regiões de soldas a pontos de aços de alta resistência revestidos com zinco. $O$ metal líquido, neste caso, consiste em ligas de $\mathrm{Zn}$-Cu provenientes da combinação de cobre dos eletrodos de soldagem com o zinco do revestimento, que penetra em contornos de grãos, reduzindo a sua energia coesiva. Sob solicitação mecânica, tal fragilização pode ocasionar origem às trincas. Neste trabalho foram investigadas as condições de formação de trincas por LME na soldagem de aços DP da classe de $600 \mathrm{MPa}$ de limite de resistência galvanizado por imersão a quente (HDG - GI). Verificou-se, em todas as condições de soldagem avaliadas, a penetração do metal líquido na superfície da solda. A ocorrência de trincas, no entanto, só foi constatada em condições de soldagem que implicaram na geração de tensões. Tais tensões foram intensificadas com refrigeração inadequada, causada por diferentes vazões de água nos eletrodos inferior $(1,5 \mathrm{l} / \mathrm{min})$ e superior (7,5 l/min), e/ou soldagem sequencial. Não foram observados efeitos prejudiciais de trincas por LME nas resistências estática (cisalhamento por tração) e dinâmica (fadiga sob cisalhamento).
\end{abstract}

Palavras-chave: LME; DP600; HDG-GI; Soldagem a Ponto.

\section{FORMATION OF CRACKS BY LIQUID METAL EMBRITTLEMNT ON WELDING NUGGET OF ZINC COATED DUAL PHASE STEEL}

\begin{abstract}
Dual-phase (DP) type advanced high-strength steels are applied at the automotive industry, mainly in structural vehicle components. Some of these steels are zinc coated, in order to increase the corrosion resistance. Nowadays, the mostly widely used joining process in vehicles is the resistance spot welding. Cracks by liquid metal embrittlement (LME) may occur in some regions of welding in zinc coated dual-phase steels. The liquid metal in this case, a combination of copper from the welding electrodes with zinc from the coating, penetrates the grain boundaries, thus reducing their cohesive energy. Under mechanical stresses, this embrittlement can lead to cracks. In this work the conditions for the formation of LME cracks and ways to avoid them were investigated in welding a hot dip galvanized (HDG - Gl) DP steel with $600 \mathrm{MPa}$ tensile strength. The penetration of liquid metal was observed in all welding conditions evaluated. The occurrence of cracks, however, was only noted at welding conditions which resulted in the generation of stresses. Such stresses were intensified by inadequate cooling, caused by different water flows in the upper and lower electrodes and/or in sequential welding. There were no detrimental effects of the LME cracking on the static (tensile-shear) and dynamic (tensile-shear fatigue) strengths.
\end{abstract}

Keywords: LME; DP600; Hot Dip; Resistance Spot Welding.

1 Engenheira Metalurgista, Pesquisadora, Gerência Geral de Pesquisa e Desenvolvimento, Usiminas, Ipatinga, MG, Brasil.

2 Engenheiro Mecânico, Técnico de Pesquisa, Gerência Geral de Pesquisa e Desenvolvimento, Usiminas, Ipatinga, MG, Brasil. 


\section{INTRODUÇÃO}

Os aços dual phase (DP) de alta resistência são aplicados, principalmente, na indústria automotiva, sendo utilizados em componentes estruturais e em outras peças que não envolvam grandes deformações. Alguns desses aços são revestidos com zinco e suas ligas, visando uma maior resistência a corrosão.

Atualmente, o processo de união de aços mais utilizado na indústria automotiva é de soldagem por ponto (resistance spot welding). Por esse motivo, tem-se estudado a soldabilidade de aços dual phase, investigando a qualidade de suas juntas em relação às propriedades mecânicas, associado ao seu modo de fratura.

A fragilização por metal líquido (LME, do inglês liquid metal embrittlement), consiste na penetração de um metal líquido em contornos de grãos reduzindo sua energia coesiva. Sob solicitação mecânica, tal fragilização pode ocasionar origem a trincas. Trincas decorrentes de LME têm sido observadas em regiões de soldas a pontos de aços de alta resistência mecânica (por exemplo, dual phase) revestidos com zinco [1]. O metal líquido, nesse caso, consiste em ligas $\mathrm{Zn}-\mathrm{Cu}$, de baixo ponto de fusão, proveniente da combinação do cobre dos eletrodos de soldagem com o zinco da camada de revestimento. Esse líquido penetra em contornos de grãos da zona afetada pelo calor, especificamente nas regiões em contato com os eletrodos, causando trincas [2, 3, 4].

Agashe et al. [1] observaram que a LME em aços revestidos soldados a ponto ocorre devido ao desalinhamento entre os eletrodos, aporte de calor, desgaste excessivo e resfriamento insuficiente da ponta do eletrodo.

De acordo com Sakuma et al. [5], as trincas por LME podem ocorrer devido à geração de tensões internas durante a solidificação da lente na superfície da chapa com o uso de correntes excessivas de soldagem. Além disso, a trinca pode ocorrer na periferia da lente adjacente à região corona.

\section{MATERIAIS E MÉTODOS}

O aço utilizado no presente estudo foi da classe DP600, na espessura de 1,50 mm, com massa de revestimento de $60 \mathrm{~g} / \mathrm{m}^{2}$, obtido por processo de galvanização por imersão a quente sem tratamento térmico da camada de zinco (Gl). A composição química do substrato é dada na tabela 1.

Tabela 1. Composição química (\% p/p) do aço DP600.

\begin{tabular}{cccccc}
\hline Material & $\mathbf{C}$ & $\mathbf{M n}$ & $\mathbf{S i}$ & $\mathbf{P}$ & $\mathbf{S}$ \\
\hline DP600 Gl & 0,07 & 1,70 & 0,02 & 0,02 & 0,01 \\
\hline
\end{tabular}

Para soldagem utilizou-se um equipamento de corrente alternada (AC). O eletrodo foi de Cu-Cr-Zr, tipo domo, grupo A, classe 2, de acordo com a norma AWS C1.4M [6].

$\mathrm{Na}$ etapa de determinação de correntes mínimas e máximas (Imín e Imáx) foram fixados os seguintes parâmetros de soldagem: tempo de pré-pressão de 40 ciclos, a vazão de água de $1,8 \mathrm{~L} / \mathrm{min}$ e o tempo de retenção de 10 ciclos. Foram variados os parâmetros tempo de soldagem: 8/2/8 ciclos (solda/pausa/solda) e 18 ciclos, assim como a força entre eletrodos: $4000 \mathrm{~N}$ e $4900 \mathrm{~N}$.

Para melhor compreensão dos resultados durante a observação das trincas por LME, em todos os campos de soldabilidade, as correntes foram determinadas numa faixa de $I_{0 \%}$ a $I_{100 \%}$, que significam, respectivamente, de $I_{\text {mín a }} I_{\text {máx. }}$ 


\subsection{Avaliação da Influência dos Parâmetros de Soldagem na Qualidade da Solda}

Após a determinação das correntes $I_{\text {mín e }} I_{\text {máx }}$ foi estabelecido um valor fixo de corrente $(9,4 \mathrm{kA})$, de força entre eletrodos $(4000 \mathrm{~N})$ e do tempo de soldagem (18 ciclos) a fim de descobrir as causas da LME.

Para análise da influência da vazão de água de refrigeração na ocorrência da LME, os valores dessa vazão foram diferenciados para cada eletrodo de modo a provocar gradientes de temperatura entre as regiões superior e inferior da lente de solda, conforme pode ser visto na tabela 2 .

Tabela 2. Valores de vazão nos eletrodos superior e inferior.

\begin{tabular}{ccc}
\hline Etapa & $\begin{array}{c}\text { Vazão no } \\
\text { Eletrodo } \\
\text { Superior (L/min) }\end{array}$ & $\begin{array}{c}\text { Vazão no } \\
\text { Eletrodo Inferior } \\
\text { (L/min) }\end{array}$ \\
\hline 1 & 7,5 & 1,5 \\
\hline 2 & 1,5 & 7,5 \\
\hline 3 & 1,5 & 1,5 \\
\hline 4 & 7,5 & 7,5
\end{tabular}

Em outro estágio foi verificado o efeito do desalinhamento dos eletrodos na ocorrência de trincas por LME. As soldagens foram realizadas com eletrodos alinhados e depois desalinhados axialmente, com uma distância (d) de aproximadamente $2 \mathrm{~mm}$, figura 1 .

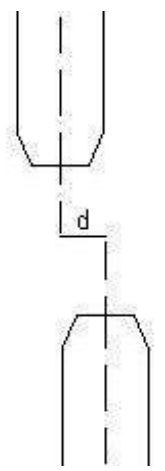

Figura 1. Representação esquemática de desalinhamento axial do eletrodo.

Com os mesmos parâmetros de soldagem utilizados e vazões diferentes para os eletrodos (7,5 L/min inferior e 1,5 L/min superior), foram avaliadas duas formas de soldagem: i) por pontos em sequência contínua com o intervalo entre as soldas de 90 ciclos (1,5 s), figura 2 , e ii) com um ponto simulando a solda no corpo de prova para ensaio de cisalhamento, figura 3. Essa avaliação foi realizada para verificar se é possível provocar trincas por LME em corpos de prova para os ensaios mecânicos de cisalhamento e fadiga.

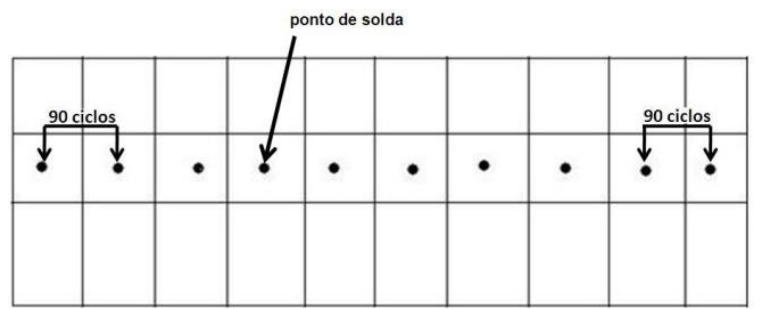

Figura 2. Esquema de sequência de pontos de solda. 


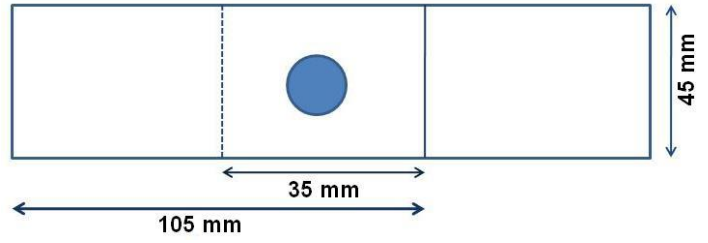

Figura 3. Geometria do corpo de prova para ensaio de cisalhamento.

As superfícies de todas as lentes obtidas durante as etapas: de determinação das correntes limites de soldagens ( $I_{\text {min }}$ e $I_{\text {máx }}$ ), de avaliação do efeito da vazão de água, da influência do desalinhamento de eletrodos e do sequenciamento de soldagem foram observadas por microscopia óptica e ensaio com líquido penetrante. Aquelas que exibiram trincas na superfície foram cortadas em seção, para serem melhor analisadas, conforme representado na figura 4. Após o embutimento, as trincas, em seção, foram novamente analisadas via microscopia óptica e também por MEV/EDS.

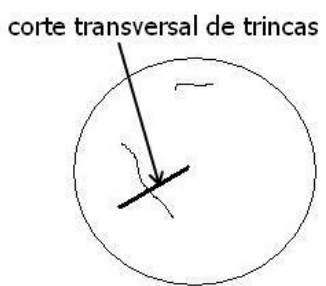

Figura 4. Representação esquemática do corte transversal à trinca na superfície da lente de solda [3].

Foram realizados ensaios mecânicos estático de cisalhamento e dinâmico de fadiga em cisalhamento. Esses ensaios foram aplicados em juntas com e sem LME para avaliar a influência desse defeito nas resistências estática e dinâmica.

Os parâmetros utilizados para a soldagem dos corpos de prova para os ensaios mecânicos foram: $4000 \mathrm{~N}$ de força entre eletrodos, 40 ciclos de pré-pressão, 10 ciclos de retenção, 8/2/8 ciclos de soldagem e vazão de $7,5 \mathrm{~L} / \mathrm{min}$ para eletrodo inferior e de 1,5 L/min para eletrodo superior.

O ensaio em fadiga foi conduzido de acordo com a norma JIS Z3138 [7]. Para execução dos ensaios, utilizou-se a razão entre as cargas de $R=0,1$ e a frequência de $25 \mathrm{~Hz}$. O corpo de prova foi confeccionado, conforme mostrado na figura 5.

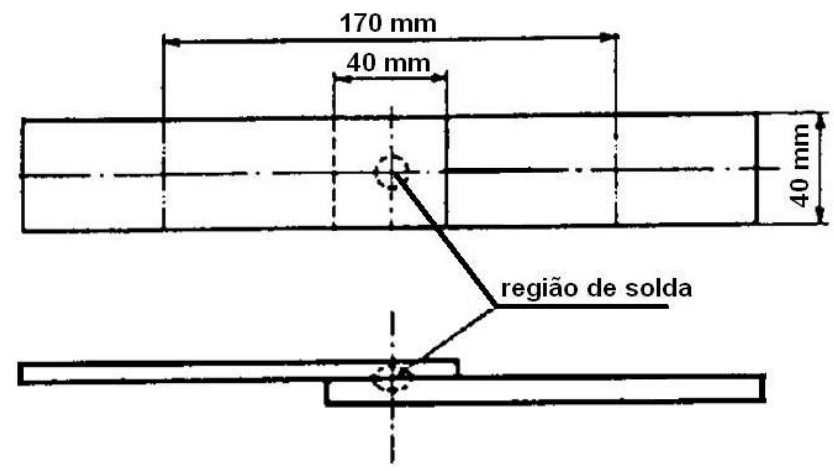

Figura 5. Geometria dos corpos de prova para o ensaio de fadiga por cisalhamento [7].

Os ensaios de dureza foram realizados com uma carga de 0,3 kgf ao longo da região soldada em dois corpos de prova: um com e o outro sem LME. Na região do metal base foram aplicadas indentações a intervalos de $0,5 \mathrm{~mm}$ e na 
zona termicamente afetada a distância entre as medições foi de 0,2 mm [8], conforme figura 6.

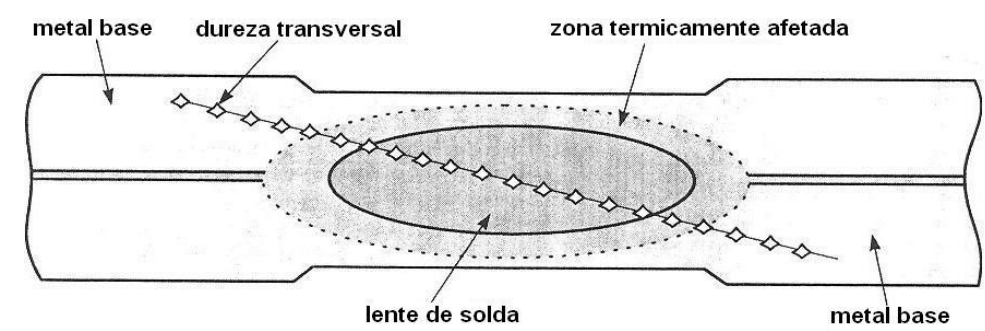

Figura 6. Esquema de análise de perfil de dureza em seção de lentes de solda a pontos [8].

\section{RESULTADOS E DISCUSSÃO}

\subsection{Determinação das correntes $I_{\min }$ e $I_{\text {máx }}$}

Os valores de correntes obtidos para distintos valores de força e tempo de soldagem podem ser visualizados na figura 7.

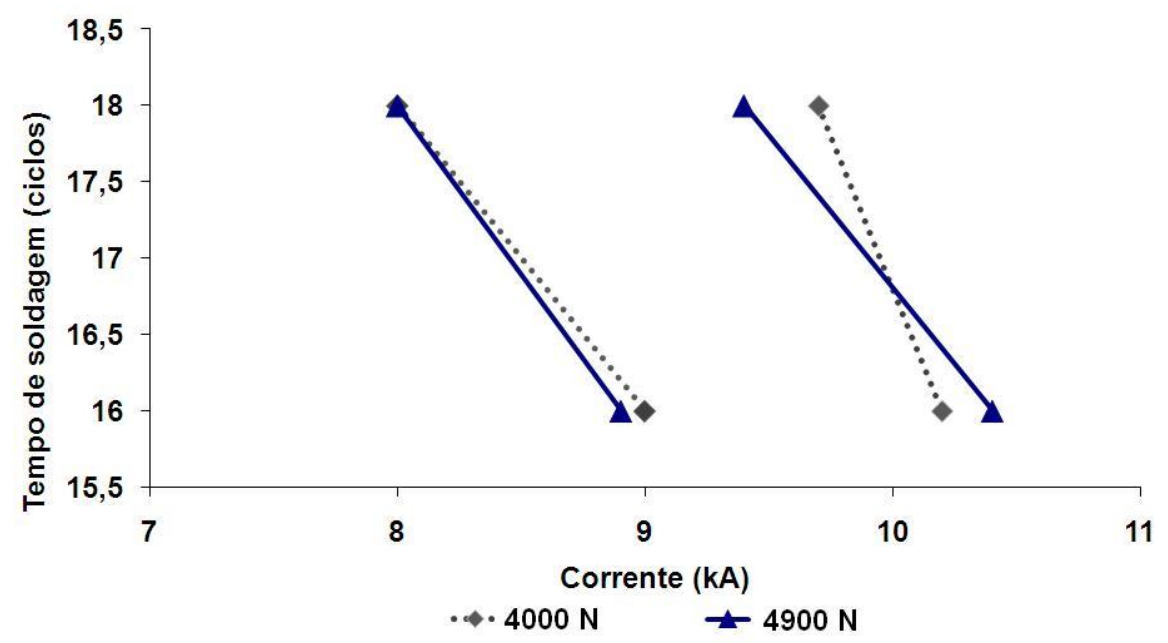

Figura 7. Campos de soldabilidade de aço DP600 (Gl).

Durante a etapa de definição de correntes de soldagem foi verificada a presença de trincas na superfície das soldas, figura 8. Após análises em seções ao longo da espessura, notou-se que estas se propagavam para o interior da lente, figura 9. As trincas só não foram observadas para $I_{0 \%}\left(I_{m i ́ n}\right)$.

Independentemente dos parâmetros utilizados na etapa de definição de correntes de soldagem, foram observadas várias trincas de tamanhos diferentes em uma mesma lente. A maior parte das trincas com o tamanho acima de $400 \mu \mathrm{m}$ ocorreu quando do

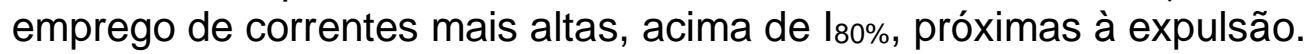




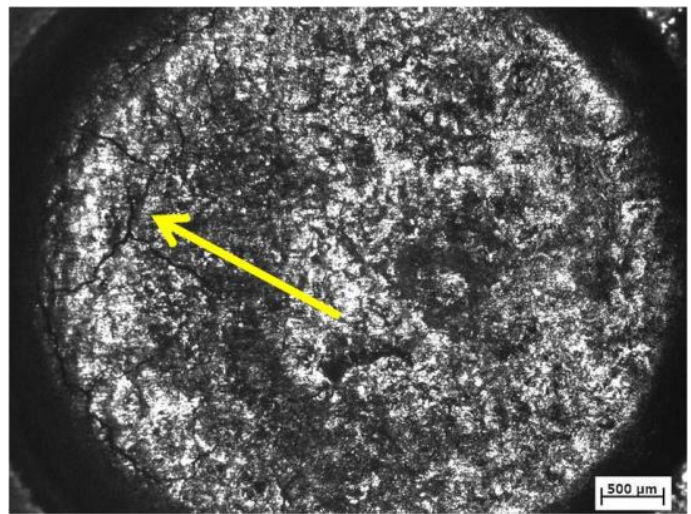

Figura 8. Aspecto típico da superfície superior da lente de solda com trincas. (Parâmetros de soldagem: $\mathrm{I}_{83} \%, 8 / 2 / 8$ ciclos de soldagem, $\left.4000 \mathrm{~N}, 1,8 \mathrm{~L} / \mathrm{min}\right)$.

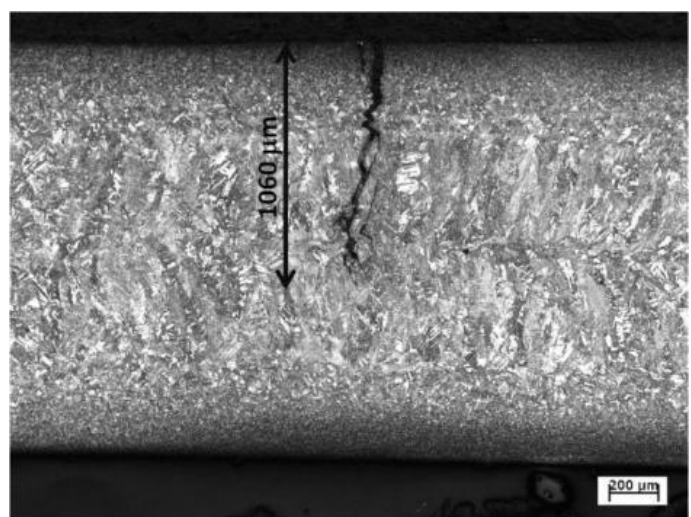

Figura 9. Aspecto típico da trinca na superfície superior da lente de solda. Ataque: Nital 4\%. (Parâmetros de soldagem: $1_{87 \%}, 4900$ N, 1,8 L/min, 18 ciclos de soldagem).

Após análises via MEV/EDS pode-se verificar que as trincas foram causadas por fragilização do metal líquido (LME), figura 10.

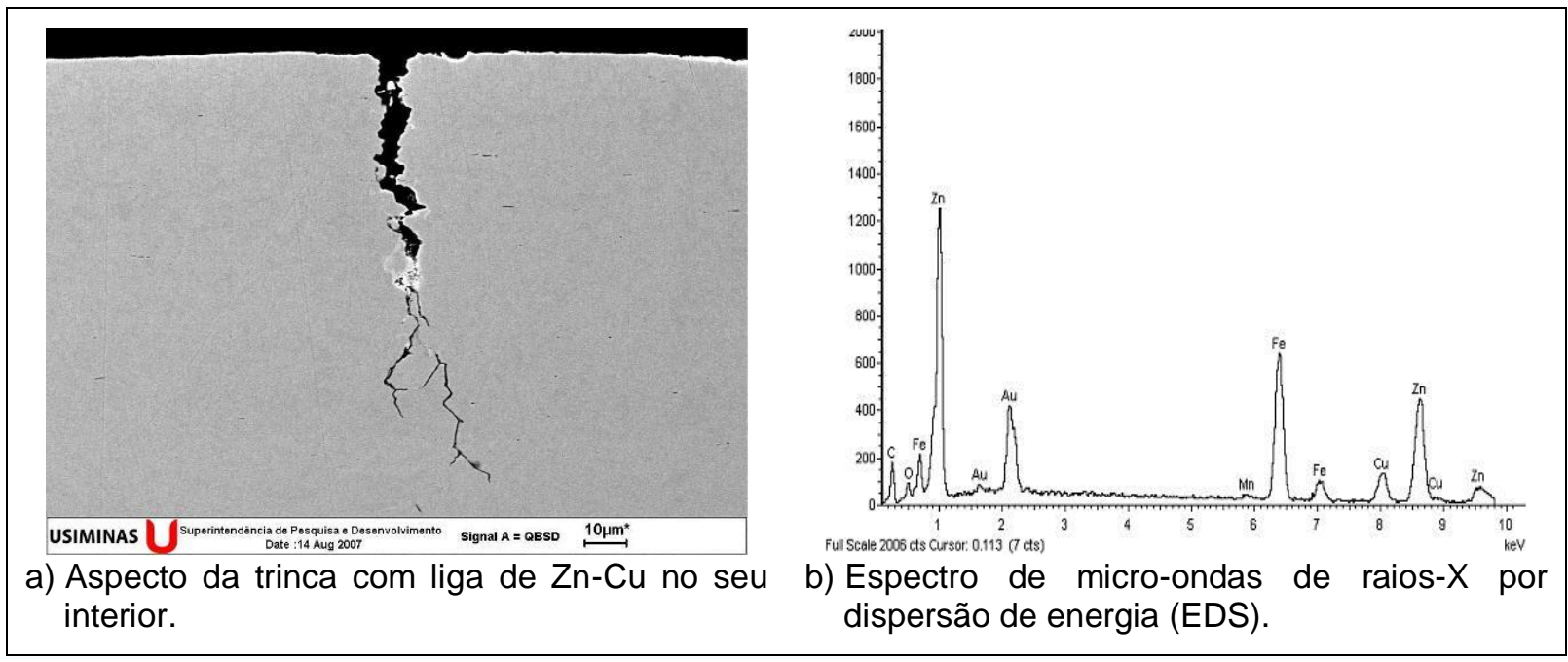

Figura 10. Aspecto da trinca com liga de $\mathrm{Zn-Cu}$ localizada na região superior da lente de solda. (Parâmetros de soldagem: $I_{85 \%}, 4900$ N, 1,8 L/min, 8/2/8 ciclos de soldagem). 


\subsection{Efeito da Vazão de Água de Refrigeração na Ocorrência de Trincas}

Nos casos em que as vazões de água foram diferentes nos eletrodos superior e inferior, identificaram-se trincas em quase todas as lentes de solda, após ensaio com líquido penetrante. Para maior vazão no eletrodo superior $(7,5 \mathrm{~L} / \mathrm{min})$ e menor no inferior $(1,5 \mathrm{~L} / \mathrm{min}), 83 \%$ das lentes exibiram trincas na parte superior e nenhuma trinca na parte inferior, figura 11. Enquanto que para maior vazão no eletrodo inferior, $31 \%$ apresentaram trincas na parte inferior, e nenhuma trinca no lado superior. Não foram observadas trincas em nenhum dos lados nas lentes de solda quando os eletrodos inferior e superior foram submetidos às mesmas vazões, primeiramente de $7,5 \mathrm{~L} / \mathrm{min}$ e depois de $1,5 \mathrm{~L} / \mathrm{min}$.

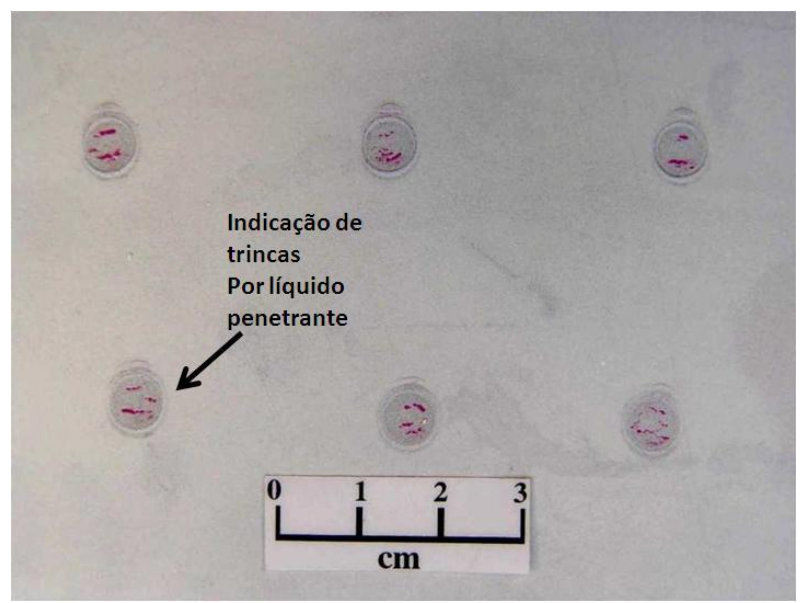

Figura 11. Detalhe de verificação de LME em superfície superior de lentes de solda após ensaio com líquido penetrante.

Apesar da constatação de trincas por LME, quando os eletrodos superior e inferior tiveram vazões de água de refrigeração muito diferentes, não foi possível determinar a razão para esse fenômeno. Uma possível explicação estaria relacionada às diferenças de velocidade de resfriamento na região de solda. Sabe-se que o resfriamento da solda ocorre a partir da periferia e em regiões em contato com os eletrodos. Dessa forma, se uma região da solda resfriasse mais rapidamente que a outra, tensões seriam geradas entre essas regiões. Consequentemente, se a região com líquido fragilizante alojado nos contornos de grão austeníticos fosse submetida a tensões trativas, haveria ocorrência de trincas.

\subsection{Influência do Desalinhamento de Eletrodos na Ocorrência de Trincas}

Não foram identificadas trincas nas superfícies inferior e superior de lente de solda com desalinhamento axial de eletrodos.

Acredita-se que o desalinhamento axial de eletrodo não influencie na ocorrência de LME, pois esse fenômeno está diretamente relacionado com o resfriamento da lente de solda. 


\subsection{Efeito da Sequência de Soldagem}

Após a soldagem a pontos em sequência, realizou-se o ensaio de líquido penetrante e verificou-se que existiam trincas em todas as lentes de solda, figura 12. Em soldagens realizadas em corpos de prova soldados individualmente não foram notadas trincas após ensaio com líquido penetrante.

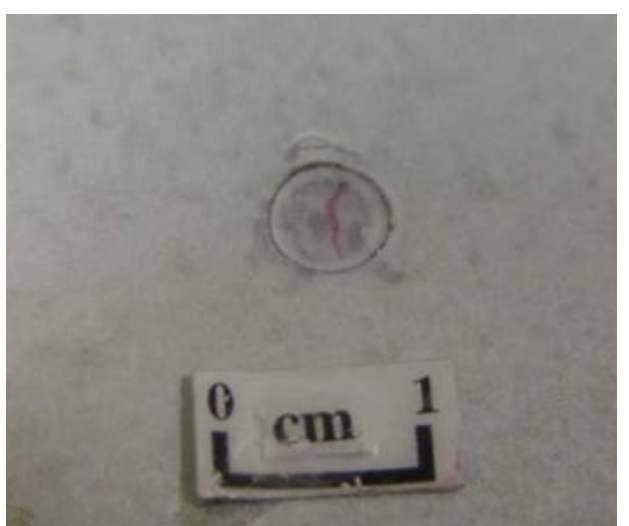

Figura 12. Detalhe de lente de solda obtido após ensaio com líquido penetrante em corpos de prova soldados a pontos em sequência.

Deve ser ressaltado que de acordo com Wolff [9] e Eagar et al. [10] a vazão de água não tem influência significativa no resfriamento de eletrodo quando se considera somente um ponto de solda, como no caso de soldagem de corpos de prova individuais, pois o efeito da vazão depende da altura da face do eletrodo e do fluxo de água. Sendo assim, o gradiente de temperatura nas regiões superior e inferior seria insuficiente para provocar trincas. Por outro lado, em soldagem sequencial a vazão de água é importante para o resfriamento, uma vez que haveria a fusão de eletrodos se o resfriamento fosse feito somente pela dissipação de calor dos eletrodos para as chapas. No presente estudo, ficou claro que a vazão de água, interferiu na refrigeração de eletrodos durante a soldagem por sequência. Vazões diferentes provocaram um padrão de resfriamento certamente diferente daquele que ocorreria se as vazões fossem idênticas.

\subsection{Ensaio Estático de Cisalhamento}

Todos os corpos de prova com e sem trinca analisados apresentaram fratura do tipo interfacial, figura 13. Os corpos de prova com trinca, soldados em sequência, apresentaram diâmetros de botões de solda menores do que os soldados individualmente, por consequência os resultados do ensaio em cisalhamento foram menores, conforme pode ser observado na tabela 3. De acordo com Zhang et al. [11], quando a soldagem é realizada por sequência ocorre perda da corrente (corrente parasita), esse efeito é chamado de desvio (shunting). A corrente é desviada de seu destino diminuindo a densidade de corrente para a próxima lente.

Como as trincas por fragilização por metal líquido estão localizadas na superfície da solda e, em alguns casos, até na zona fundida, estas não interferiram no modo de fratura, pois estavam localizadas longe da região entre as duas chapas onde ocorreu a ruptura. 
Tabela 1. Resultados de ensaio de resistência ao cisalhamento do aço DP600 (GI).

\begin{tabular}{ccc}
\hline & $\begin{array}{c}\text { Amostra com } \\
\text { trinca }\end{array}$ & $\begin{array}{c}\text { Amostra sem } \\
\text { trinca }\end{array}$ \\
\hline $\begin{array}{c}\text { Carga máxima } \\
\text { aplicada valor médio } \\
\text { em kN }\end{array}$ & 15 & 17 \\
\hline
\end{tabular}

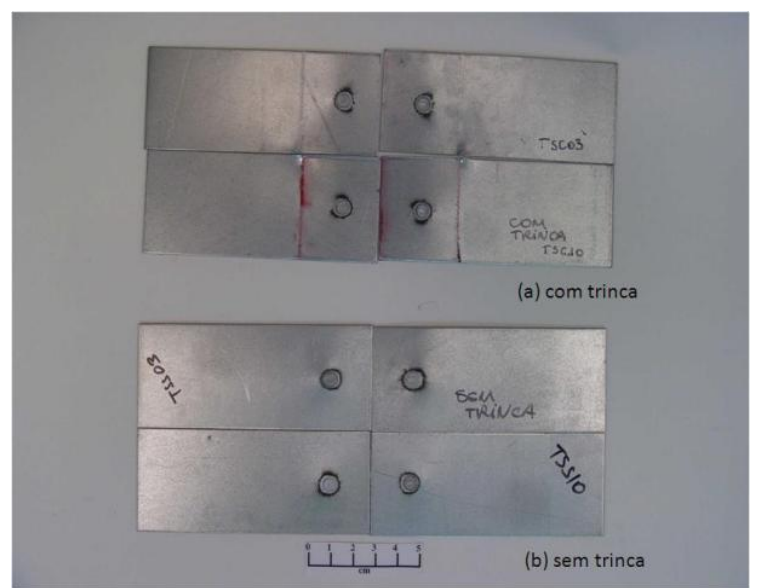

Figura 13. Fratura do tipo interfacial em ensaio tração por cisalhamento para as lentes de solda com trinca (a) e sem trinca por LME (b).

\subsection{Ensaio de Fadiga por Cisalhamento}

A curva S-N em ensaio de fadiga por cisalhamento pode ser vista na figura 14. Não foram observadas nas superfícies superiores das lentes de solda diferenças significativas em relação à vida em fadiga entre os corpos de prova com e sem trincas (LME). As superfícies de fratura de amostras com e sem trincas apresentaram aspectos similares, principalmente na região de propagação.

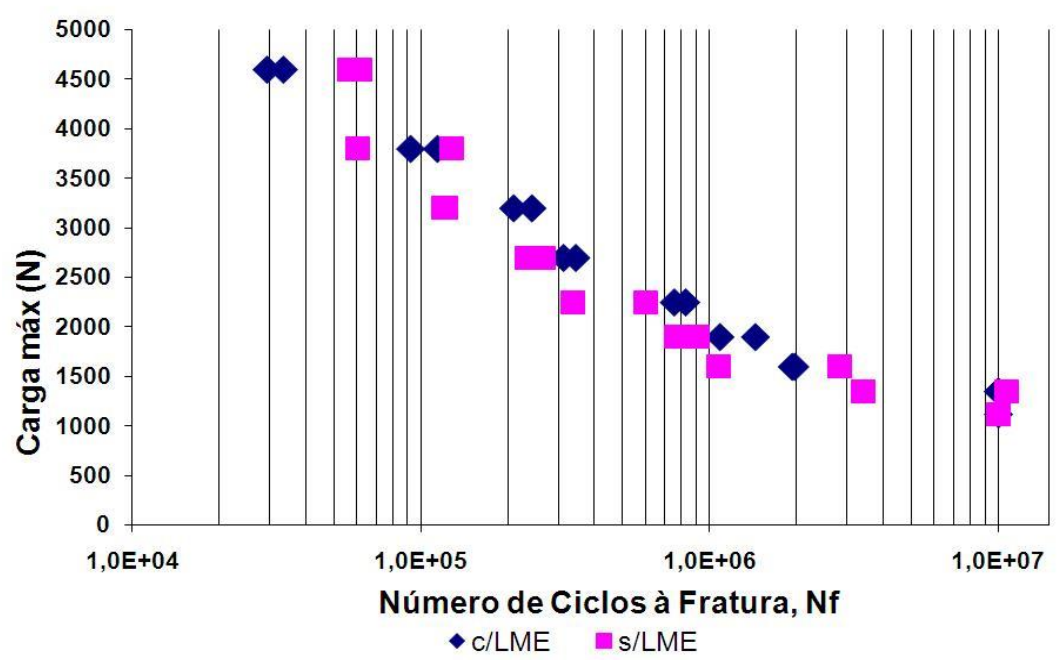

Figura 14. Curvas de fadiga por cisalhamento em lentes de solda com trincas e sem trincas obtidas por soldagem a ponto para aço DP600 (Gl). 


\subsection{Dureza}

O aspecto da lente e o perfil de dureza ao longo da seção de amostras com e sem LME podem ser vistos nas figuras 15 e 16. Observa-se queda de dureza na região da trinca, diferentemente da amostra sem LME, que apresenta uma linearidade ao longo na região da zona fundida.

Mesmo havendo diferenças entre a dureza em regiões com e sem LME, não foi observada influência da trinca sobre a resistência a fadiga e nem sobre a resistência estática ao cisalhamento.

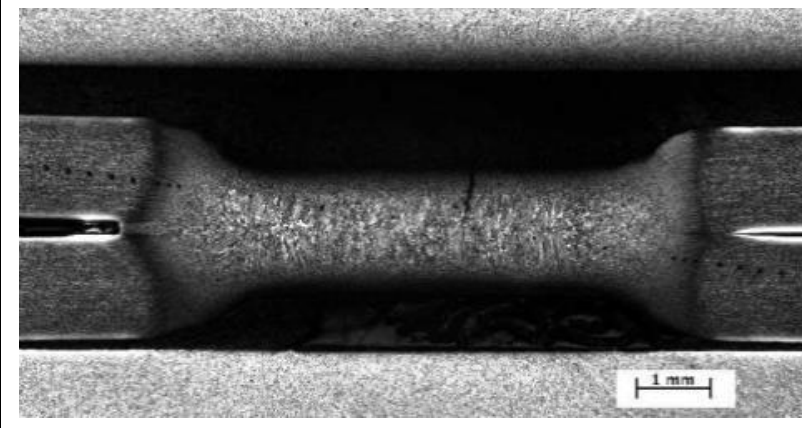

a) Aspecto da seção da lente de solda analisada.

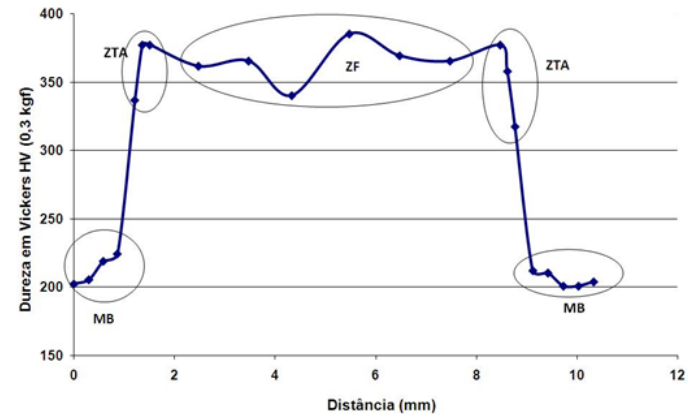

b) Perfil de dureza ao longo desta seção.

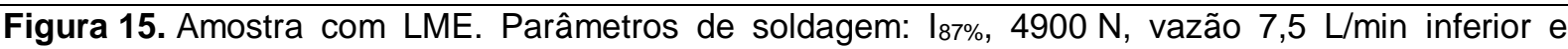
$1,5 \mathrm{~L} / \mathrm{min}$ no superior, $8 / 2 / 8$ ciclos de soldagem.

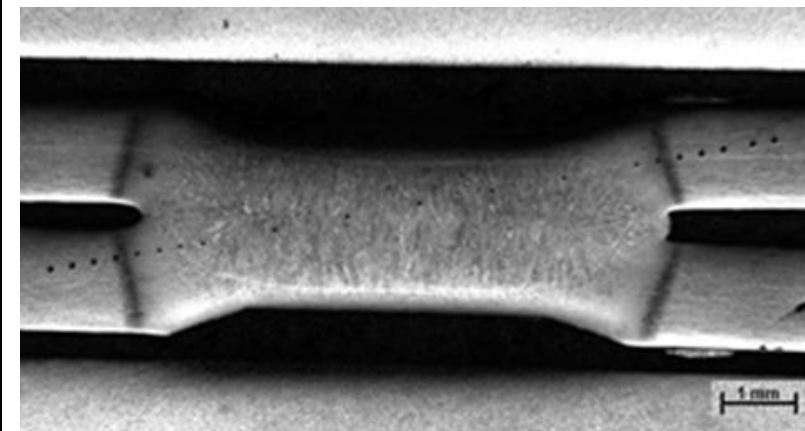

a) Aspecto da seção da lente de solda analisada.

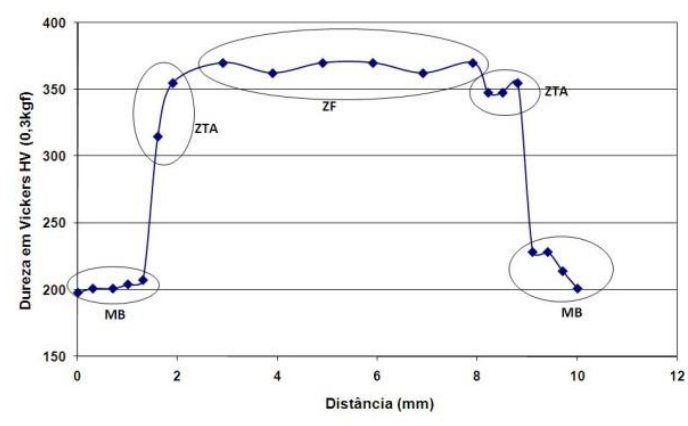

b) Perfil de dureza ao longo desta seção.

Figura 16. Amostra sem LME. Parâmetros de soldagem: $\left.\right|_{83 \%}, 4000 \mathrm{~N}$, vazão 7,5 L/min, 8/2/8 ciclos de soldagem. 


\section{CONCLUSÃo}

As trincas por fragilização por metal líquido (LME) ocorreram somente na superfície da solda em regiões de contato com os eletrodos. Ligas $\mathrm{Zn}-\mathrm{Cu}$, no estado líquido, penetram nos contornos de grãos austeníticos da zona afetada pelo calor de soldagem durante a etapa de aquecimento da solda. Posteriormente, tensões geradas por gradientes de temperatura durante o resfriamento da solda, podem provocar a separação (trinca) desses contornos. Eventualmente ocorreu propagação adicional da trinca ainda ao longo de contornos de grãos, por exemplo, na lente de solda.

A combinação do emprego de vazões de água de resfriamento dissimilares nos eletrodos com a realização de soldagem de forma sequencial foi determinante para a ocorrência de trincas. Acredita-se que tal combinação gerou tensões elevadas na região de solda, que provocaram as trincas. Em soldas isoladas não houve ocorrência de trincas, independente do tipo de vazão.

As trincas ocorreram em todos os níveis de corrente do campo de soldabilidade, exceto para a corrente mínima ( $\left.I_{\text {mín}}\right)$ e independeram da força entre eletrodos e de seu alinhamento.

Não foi verificado efeito de trincas por LME nas resistências estática e dinâmica de soldas a pontos. A explicação mais provável para isso foi que regiões de iniciação e propagação de trincas geradas nesses ensaios não coincidiram com a região com trincas por LME.

\section{REFERÊNCIAS}

1. Jiang C, Agashe S, Zhang J, Zhang H. Liquid Metal Embrittlement in Resistance Spot Welds of AHSS Steels. American Welding Society Annual Convention. Detroit; 2003.

2. Takeda T. Evaluation Method of Zinc Induced Cracking. Journal of the Japan Welding Society, 2002; 71 (4): 234-240.

3. Suzuki K, Aihara S, Ichikawa K, Yajima H. Study of Practical use of welding consumables for steel of hot dip galvanizing bath. Quarterly Journal of the Japan Welding Society. 2000; 18: 119-125.

4. Jiang CS. Reduction of Liquid Metal Embrittlement in Resistance Spot Welds of Zinc-Coated Advanced High-Strength Steels. Sheet Metal Welding Conference XIII. Livonia: AWS; 2008.

5. Sakuma Y, Takahashi Y. Spot-weldability of galvannealed steel sheets with a tensile strength of $590 \mathrm{MPa}$. JSAE Review, 2002; 23 (1):142-144.

6. American Welding Society. C1.4M/C1.4. Specification for resistance welding of carbon and Low-Alloy Steels. AWS; 1999.

7. Japanese Industrial Standard. JIS Z 3138. Method of Fatigue Testing for Spot Welding Joint; 1989. 
8. American Welding Society. D8.9M. Recommended Practices for Test Methods for Evaluating the Resistance Spot Welding Behavior of Automotive Sheet Steel Materials. Miami: AWS; 2002.

9. Wolff MA. Soldabilidade de aços dual phase 600 e 800 via processo de soldagem a pontos média frequência corrente contínua (MFDC) e corrente alternada (AC) [dissertação de mestrado]. Uberlândia: Universidade Federal de Uberlândia, Faculdade de Engenharia Mecânica; 2008.

10. Eagar TW, Kim E. Transient Thermal Behavior in Resistance Spot Welding. Sheet Metal Welding Conference III; 1988 Out 25-27; Detroit, MI. 